\title{
Empoderamento e interdisciplinaridade no combate às violências contra a mulher
}

\author{
Dicionário Feminino da Infâmia: \\ acolhimento e diagnóstico de \\ mulheres em situação de \\ violência
}

FLEURY-TEIXEIRA, Elizabeth; MENEGHEL, Stela Nazareth (Orgs.).

Rio de Janeiro: Editora FIOCRUZ, 2015, 422p.

No Brasil, 91 mil mulheres foram assassinadas entre 1980 e 2010, 43,5 mil só na última década. Em $81 \%$ dos casos os autores das agressões tiveram algum vínculo afetivo com as vítimas (Julio Jacobo WAISELFISZ, 2011, p. 5). Esses são alguns dados resgatados pelo Dicionário Feminino da Infâmia: acolhimento e diagnóstico de mulheres em situação de violência, organizado por Elizabeth Fleury-Teixeira e Stela Nazareth Meneghel e lançado pela Editora Fiocruz. Mas os números, por si só, não dão conta das violências contra as mulheres, multiplicadas em doméstica, sexual, obstétrica, psicológica, racial, sexual, simbólica, nem das muitas opressões que se escamoteiam nas situações cotidianas, nas instituições públicas e que se disfarçam nos relacionamentos mais celebrados. Por isso, o Dicionário vai além dos números.

A obra elenca 187 verbetes, assinados por diversas/os especialistas da saúde, do direito, das ciências sociais e humanas, voltados aos conceitos, às normas e para os procedimentos relacionados ao atendimento a mulheres em situação de violência. Acima de tudo, as páginas fazem com que se pense na própria condição da mulher hoje, como pertencente a uma categoria múltipla, instigando reivindicações, bem como novas práticas e políticas públicas. Como complementou no prefácio Nilcéa Freire (2015, p. 9), representante da Fundação Ford no Rio de Janeiro e ex-ministra da Secretaria de Políticas para as Mulheres, o livro apresenta os temas em sua dimensão histórica, considerando o contexto de luta das mulheres por seus direitos, sendo leitura fundamental para quem trata de seus direitos humanos. A obra, inclusive, homenageia a socióloga e pensadora feminista Heleieth Saffioti, falecida em 2010, aos 76 anos, que ao longo de toda a sua trajetória se dedicou a essas causas.

É possível identificar, entre os eixos dos vocábulos do Dicionário, temáticas referentes a direitos civis e políticas públicas voltadas para as mulheres; teoria feminista; atuação e origem de movimentos sociais; esclarecimentos sobre as violências contra a mulher e suas formas de tratamento. Segundo as organizadoras, a intenção é fazer dialogar vários campos de conhecimento relacionados à realidade das violências de maneira didática, acessível, para consulta rápida. A obra pode ser uma referência até para leigas/os, apesar de alguns conceitos exigirem uma bagagem mais especializada, da área da saúde ou do direito, especialmente, a exemplo de 'imputabilidade' ou 'protocolos de saúde mental e reprodutiva'. De qualquer modo, se nomear não deixa de ser um recurso para escancarar relações de exploração e de dominação, como também um ponto de partida para a busca de rotas alternativas e processos de liberdade, torna-se indispensável tratar de questões como delegacias de mulheres, a Lei Maria da Penha ou as diversas violências que recaem sobre os ombros femininos. 
Na obra, Latif Antonia Cassab $(2015$, p. 376 378), ao tratar de violência de gênero, explica, em referência a diversos autores, que o fenômeno é complexo e está relacionado a diversas formas de violência. No entanto, de modo geral, violência de gênero ocorre com base em relações assimétricas e hierarquizadas, ou seja, insere-se em uma relação desigual e/ ou de subordinação, "interferindo de forma negativa no desenvolvimento pleno do sujeito agredido" (Silvia KOLLER, 2000 apud CASSAB, 2015, p. 377). Portanto, firma-se no contexto de sociedades patriarcais, que estabelecem socialmente o homem como superior. Mesmo assim, a autora observa que se trata de uma relação de poder que não é absoluta nem estática, porém, dinâmica e relacional. Nesse sentido, mesmo quando se encontra em situação de vítima, a mulher tem possibilidade para ter autonomia e poder de superação dessa condição, lembra Cassab ao citar o trabalho de Cecília MacDowell Santos e Wânia Pasinato Izumino (2005 apud CASSAB, 2015, p. 378).

Desse modo, é possível notar, no livro, que há uma preocupação não apenas em fornece um panorama sobre as violências contra a mulher mas também discussões e proposições de mudanças nos contextos sociais. Portanto verbetes como 'culpabilização' e 'invisibilidade da violência' fazem pensar em como as culpas atribuídas às mulheres são antigas, tendo apoio nas religiões e até na filosofia, sendo fundamenta desnaturalizar, por meio de uma atitude crítica, os processos de legitimação dessa suposta inferiorização feminina.

Também há espaço, no Dicionário, para problematizações quanto à saúde pública. Assim, ao tratar de 'aborto', as estudiosas Claudia Bonan Jannotti e Gilberta Santos Soares (2015, p. 17-20) apontaram a necessidade de se contornar a desinformação, os tabus e estigmas relacionados ao procedimento, inclusive entre os profissionais de saúde, para uma assistência plena às mulheres em situação de abortamento.

Quanto à abordagem de conceitos da teoria feminista, vale lembrar Sandra Regina Goulart Almeida (2013) que, em edição da Revista Estudos Feministas, apontou sobre a importância de se desestabilizar as matrizes de poder, tecendo-se uma narrativa crítica dos constructos sociais e culturais. Assim, visando esse posicionamento desestabilizador e intervencionista, a estudiosa defende a associação da teoria feminista com o pós-colonialismo, pensando-se nas condições materiais e existenciais das mulheres. Nesse sentido, pode-se creditar mérito ao Dicionário, que converge essas perspectivas, tratando de questões teóricas e práticas referentes à vitimização, nas situações em que as mulheres são alvo de violência, e ao empoderamento, destacando-se a tomada de consciência e o poder de ação feminina.

Mesmo assim, como o próprio Dicionário coloca, não se pode perder de vista a categoria 'mulheres' como complexa, heterogênea e atravessada por múltiplos aspectos identitários, como classe e raça. Nesse sentido, torna-se indispensável não apenas associar diferentes perspectivas nas discussões como também conferir espaço a "outras vozes", como propuseram em outro artigo publicado naquela mesma edição da REF, Claudia Andréa Mayorga Borges, Alba Coura, Nerea Miralles e Vivane Martins Cunha (2013). Ou seja, segundo estas autoras, é preciso também olhar para as feministas que abordam a crítica de gênero a partir do racismo, do colonialismo, da política heterossexual. Essas diferentes leituras podem promover rupturas epistemológicas e deslocamentos no feminismo, saindo de uma teoria linear que tem apenas a Europa e os Estados Unidos como referênCia (MAYORGA; COURA; MIRALLES; CUNHA, 2013 p. 470).

A promoção a essas "outras vozes", embora apareça de forma tímida em outros vocábulos relacionados ao feminismo no Dicionário, são marcantes no verbete 'interseccionalidade', assinado por Mayorga (2015, p. 184-187) e que sugere como bibliografia, inclusive, trabalhos de Ochy Curiel, Gloria Anzaldúa e Monique Wittig, pensadoras conhecidas por abordar as críticas de gênero a partir de propostas diferenciadas. Como explica Mayorga (2015, p. 184), remetendo a pesquisadores como Cristiano Rodrigues, o conceito de interseccionalidade foi elaborado pelas feministas negras dos anos de 1980, na proposição de um pensamento relacional e articulado das categorias de classificação dos sujeitos. Seria uma forma de responder à necessidade de compreender formas de opressão articuladamente, bem como de construir enfrentamentos que contemplem as demandas de diversas mulheres, como resume a autora.

Propondo, então, o debate à condição das mulheres na sociedade brasileira sob uma série de sentidos, o Dicionário parece ser um aliado na busca por transformações sociais. A própria trajetória das organizadoras do livro contribui para esse viés. Stela Nazareth Meneghel, além de doutora em medicina/ ciências médicas, com pós-doutorado em psicologia social e ampla trajetória profissional, 
tem experiência na área de saúde coletiva em vigilância da saúde, vulnerabilidades, gênero e violências, enquanto Elizabeth Fleury Teixeira, mestra em sociologia, coordena o Comitê Nacional Pró-Equidade de Gênero e Raça da Fundação Oswaldo Cruz, entre outras ações, foi também ativista nos grupos de resistência democrática e pelos direitos das mulheres. Elizabeth foi, inclusive, uma das líderes do movimento "Quem ama não mata", de 1980 , que protestava contra o assassinato de mulheres que se afirmavam como "crimes em defesa da honra".

Esse é o sentido que relacionamos ao título do livro em questão. Infâmia denota má fama e desonra, não deixa de remeter a essa "honra" como padrão social que garantiu - e em muitos aspectos ainda garante - os privilégios masculinos e que, por vezes, torna-se justificativa dos bárbaros índices de violência contra as mulheres. Infâmia, portanto, não deixa de ser uma forma de resistência a esse padrão. Uma resistência que, assim como o substantivo, é intrinsecamente feminina.

\section{Referências}

ALMEIDA, Sandra Regina Goulart. "Intervenções feministas: pós-colonialismo, poder e subalternidade". Revista Estudos Feministas, v. 21, n. 2, p. 689-700, maio-ago. 2013.

CASSAB, Latif Antonia. "Violência de gênero". In: Dicionário Feminino da Infâmia: acolhimento e diagnóstico de mulheres em situação de violência. Rio de Janeiro: Editora FIOCRUZ, 2015. p. 376-378.

FLEURY-TEIXEIRA, Elizabeth; MENEGHEL, Stela Nazareth (Orgs.). Dicionário Feminino da Infâmia: acolhimento e diagnóstico de mulheres em situação de violência. Rio de Janeiro: Editora FIOCRUZ, 2015.
FREIRE, Nilcéa. "Prefácio". In: Dicionário Feminino da Infâmia: acolhimento e diagnóstico de mulheres em situação de violência. Rio de Janeiro: Editora FIOCRUZ, 2015. p. 9-10.

JANNOTTI, Claudia Bonan; SOARES, Gilberta Santos. "Aborto". In: Dicionário Feminino da Infâmia: acolhimento e diagnóstico de mulheres em situação de violência. Rio de Janeiro: Editora FIOCRUZ, 2015. p. 17-20.

MAYORGA, Claudia; COURA, Alba; MIRALLES, Nerea; CUNHA, Vivane Martins. "As críticas ao gênero e a pluralização do feminismo: colonialismo, racismo e política heterossexual". Revista Estudos Feministas, v. 21, n. 2, p. 463484, maio-ago. 2013.

WAISELFISZ, Julio Jacobo. Mapa da Violência 2012: os novos padrões da violência homicida no Brasil. São Paulo: Instituto Sangari, 2011. Caderno Complementar 11: Homicídio de Mulheres no Brasil.

[Recebida em 11/07/2016

e aceita para publicação em 31/08/2016]

Gabrielle Vívian Bittelbrun Universidade Federal de Santa Catarina, Florianópolis, Santa Catarina, Brasil

Gabrielle Vívian Bittelbrun (gabivibi@gmail.com). Doutoranda em Literatura pela Universidade Federal de Santa Catarina, UFSC, é integrante do Núcleo Literatual - Estudos Feministas e Pós-coloniais de Narrativas da Contemporaneidade. Mestre em Jornalismo também pela UFSC (2011) e jornalista pela Universidade Estadual Paulista Júlio de Mesquita Filho, Unesp (2008). 